\title{
Rumo à Delegação Escalável e Segura de Gerenciamento de LANs para ISPs
}

\author{
Daniel C. Temp ${ }^{1,2}$, Deivid Rodrigues ${ }^{3}$, Diego Kreutz ${ }^{2}$, Rodrigo B. Mansilha ${ }^{2}$ \\ ${ }^{1}$ Inst. Federal Farroupilha, ${ }^{2}$ Univ. Federal do Pampa, ${ }^{3}$ Interneith
}

\section{Introdução}

Conforme os processos pessoais (entretenimento, financeiro, educação, segurança, saúde, etc.), suportados por uma gama crescente de dispositivos (TVs, celulares, câmeras, etc.), convergem para serviços oferecidos através da Internet das Coisas, os quesitos de Qualidade de Experiência, segurança e privacidade das Local Area Networks (LANs) residenciais aumentam em complexidade (quantidade, variedade e conflitos entre aplicações e requisitos, etc.). Consequentemente, usuários domésticos tendem a tornarem-se cada vez mais dependentes das suas LANs conectadas à Internet e estas LANs estão se tornando cada vez mais difíceis de serem gerenciadas. Por exemplo, um cliente pode desejar aumentar sua demanda por taxa de acesso à Internet motivado por uso compartilhado pela família em horário de pico ou por demandas eventuais, como partidas de futebol transmitidas exclusivamente pela Internet, mas não saber quantificar precisamente o acréscimo necessário. Outro exemplo comum são os problemas internos de funcionamento ou segurança das LANs, como aqueles decorrentes de bugs de firmware e ataques locais, que afetam a operação de serviços críticos e aplicações.

Nesse contexto, clientes podem criar expectativas irrealistas ao demandar de seus provedores de acesso (ISPs) soluções para problemas originados em suas LANs. A Figura 1 (a) ilustra duas LANs com problemas de gerenciamento que recaem sobre o ISP. Por sua vez, ISPs enfrentam desafios para gerenciar as LANs de seus clientes de forma a investigar e mitigar problemas de maneira escalável, como acesso físico ou remoto, a algum terminal interno à LAN. Atualmente, os ISPs não possuem conhecimento dos equipamentos contidos nas redes de seus clientes. A Figura 1 (b) demonstra duas alternativas para solucionar os problemas, conforme explicado a seguir.

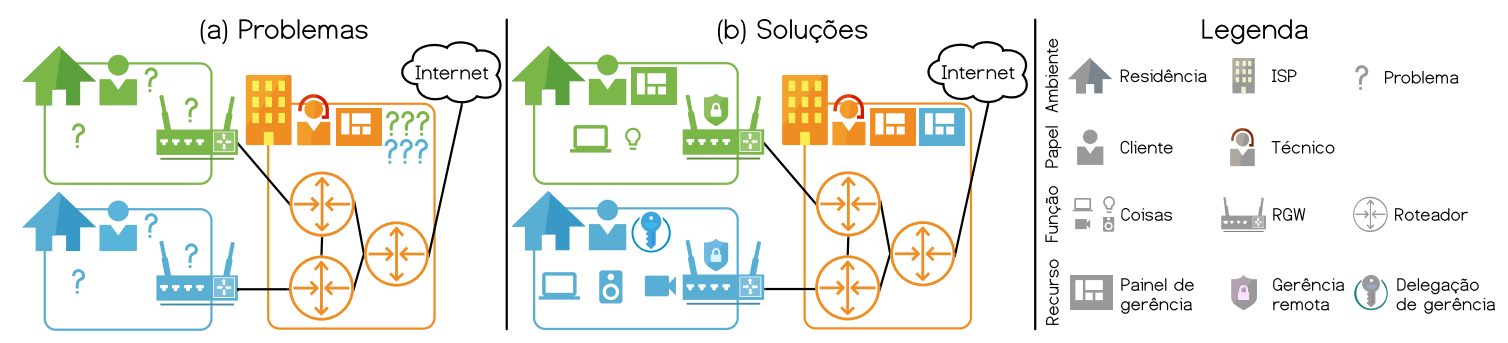

Figura 1. Exemplos de problemas e soluções para gerenciamento de LANs por ISPs

\section{Espaço de Soluções}

Um componente chave para solucionar problemas das LANs é o Residential Gateway (RGW), que conecta a LAN do cliente à rede de acesso do ISP. A indústria 
tem discutido avanços para RGW há vários anos [1]. Atualmente, existem no mercado algumas soluções paliativas especializadas [2, 3, 4]. Uma visão essencialmente acadêmica pode ser encontrada em [5], que apresenta um apanhado abrangente sobre a evolução de RGWs aproveitando conceitos de virtualização, desde as primeiras propostas conceituais, passando por atualizações recentes baseadas em Software Defined Networks (SDN) e Network Function Virtualization (NFV) e apontando direções futuras.

A Figura 1 (b) ilustra que, dispondo de um RGW moderno (i.e., que permita gerenciar a rede remotamente), o cliente poderia cumprir o papel de gerente (LAN superior) ou delegá-lo para seu ISP (LAN inferior). Como exemplo da primeira opção, Moyano et al. [6, 7] buscam tornar o gerenciamento mais amigável para o cliente. Como exemplo da segunda opção, Majord'Home [8] é um arcabouço que permite a um cliente delegar a gerência da sua LAN para seu ISP. Essa abordagem pode impactar o modelo de negócio das ISPs, como discutido em [9]. Os benefícios potenciais são demonstrados pelo estudo de caso de três serviços impactados pela possibilidade de ajuste fino: cobrança (e.g., em nível de dispositivos e serviços), controle parental (e.g., aplicações e horários) e segurança (e.g., acesso).

\section{Trabalhos em Andamento e Futuros}

O objetivo geral desta pesquisa é viabilizar a delegação escalável (i.e., padronizada entre clientes) e segura (e.g., controlada e auditável) de gerenciamento de LANs para ISPs. O desafio é superar especificidades locais como aspectos financeiros (e.g., custo total de propriedade) e sociais (e.g., conhecimento tecnológico de clientes e técnicos de ISPs). Nossa visão é simplificar ao máximo o processo de delegação de gerência para minimizar custos e facilitar a compreensão dos envolvidos e, assim, viabilizar inovação nas bordas da Internet. Os próximos passos são: a) levantamento sistemático de requisitos, $b$ ) comparação de soluções existentes, $c$ ) projeto/adequação de uma nova/existente solução, $d$ ) implementação prototípica e $e$ ) teste em ambiente real.

\section{Referências}

[1] "Home Gateway Initiative." http://www.homegatewayinitiative.org/ Acesso em: 25/07/2019.

[2] "Oi." https://www.oismart.com.br/. Acesso em: 25/07/2019.

[3] "Verizon." https://verizonwireless.com/smart-home/ Acesso em: 25/07/2019.

[4] "Orange." https://www.orange.ro/servicii-fixe/smart-home/ Acesso em: 25/07/2019.

[5] J. Proença, T. Cruz, P. Simões, and E. Monteiro, "Virtualization of residential gateways: A comprehensive survey," IEEE Communications Surveys Tutorials, 2019.

[6] R. F. Moyano, D. F. Cambronero, and L. B. Triana, "A user-centric SDN management architecture for NFV-based residential networks," Computer Standards Interfaces, 2017.

[7] R. F. Moyano, D. F. Cambronero, L. B. Triana, and C. González, "A software-defined networking approach to improve service provision in residential networks," 2017.

[8] M. Boussard, D. T. Bui, R. Douville, N. L. Sauze, L. Noirie, P. Peloso, R. Varloot, and M. Vigoureux, "The Majord'Home: a SDN approach to let ISPs manage and extend their customers' home networks," 10th Int. Conf. On Network And Service Management (CNSM), 2014.

[9] H. H. Gharakheili and V. Sivaraman, Cloud assisted home networks. 2nd Workshop On Cloudassisted Networking (CAN), 2017. 